\title{
Metabolic Syndrome in Obese Children-Clinical Prevalence and Risk Factors
}

\author{
Agnieszka Jankowska 1,*(D), Michał Brzeziński ${ }^{1}$ (D), Anna Romanowicz-Sołtyszewska ${ }^{2}$ \\ and Agnieszka Szlagatys-Sidorkiewicz ${ }^{1}$ (D) \\ 1 Department of Paediatrics, Gastroenterology, Allergology and Paediatric Nutrition, \\ Medical University of Gdańsk, 80-462 Gdańsk, Poland; michal.brzezinski@gumed.edu.pl (M.B.); \\ aga1@gumed.edu.pl (A.S.-S.) \\ 2 Department of Paediatric Cardiac Surgery in Gdańsk, Medical University of Gdańsk, 80-846 Gdańsk, Poland; \\ aneczka.romanowicz@wp.pl \\ * Correspondence: ajankowska@gumed.edu.pl; Tel.: +48-764-0468
}

Citation: Jankowska, A.; Brzeziński, M.; Romanowicz-Sołtyszewska, A.; Szlagatys-Sidorkiewicz, A. Metabolic Syndrome in Obese Children-Clinical Prevalence and Risk Factors. Int. J. Environ. Res. Public Health 2021, 18 1060. https://doi.org/10.3390/ijerph 18031060

Received: 18 December 2020

Accepted: 20 January 2021

Published: 25 January 202

Publisher's Note: MDPI stays neutral with regard to jurisdictional claims in published maps and institutional affiliations.

Copyright: (c) 2021 by the authors. Licensee MDPI, Basel, Switzerland. This article is an open access article distributed under the terms and conditions of the Creative Commons Attribution (CC BY) license (https:// creativecommons.org/licenses/by/ $4.0 /)$

\begin{abstract}
The prevalence of childhood obesity is increasing worldwide. Some obese children can go on to develop metabolic syndrome (MetS), but exactly who among them remains to be determined. The aim of this study was to indicate predisposing factors for metabolic syndrome, especially those that can be modified. The study comprised 591 obese children aged 10-12 years. They were all Caucasian residents of Gdańsk, Poland, with similar demographic backgrounds. Clinical examination, anthropometry, biometric impedance analysis, blood tests (including oral glucose tolerance tests (OGTT) and insulinemia), and dietary and physical activity evaluation were conducted. The results of our study show that the risk factors for MetS or any of its components include male sex, parental (especially paternal) obesity, low body mass at birth, as well as omitting breakfast or dinner. There are few risk factors for metabolic syndrome both in obese adults and children. Some of these predictors can be modified, especially those in relation to lifestyle. Identifying and then influencing these factors may help to reduce the development of metabolic syndrome and consequently improve health and quality of life.
\end{abstract}

Keywords: metabolic syndrome; risk factors; obesity children

\section{Introduction}

The prevalence of obesity is rapidly increasing worldwide. According to the World Health Organization (WHO), in 2016 obesity affected as many as 650 million people, and two billion adults were considered overweight (i.e., at a high risk of becoming obese); 41 million children under 5 years of age were overweight or obese and over 340 million children and adolescents aged 5-19 were overweight or obese [1]. The number of children with obesity continues to increase and it is therefore expected that complications from obesity in these age groups will also increase.

Obesity, defined as the excess of fat tissue, is wide spread all over the world and it affects all age groups [2]. Obesity, among other factors, is well known risk factor for metabolic syndrome (MetS) which comprises cardiovascular diseases (CVDs), diabetes mellitus (DM), hypertension, and atherosclerosis, as well as other complications [3]. Although the etiology of obesity is complex, genetic predisposition is permissive and actually interacts with environmental agents including physical activity and diet. Heritable factors seem to make a $40-85 \%$ contribution to obesity's etiology. Apart from genetic predisposition, other recognized constituents such as the metabolom and metabolic programming during both the gestational and post-gestational periods can be modified to some extent [4]. Consequently, development of obesity and its complications might be reduced [5].

Metabolic syndrome is a recognized consequence of obesity and it can occur as early as in adolescence. Certainly, not all obese children will develop all or any of the complications 
of obesity. Which children living with obesity are most prone to MetS remains to be fully elucidated.

In a systematic review of 85 studies in children, the median prevalence of metabolic syndrome in all populations was 3.3\% (range 0-19.2\%), in overweight children it was $11.9 \%$ (range $2.8-29.3 \%$ ), and in obese subjects it was $29.2 \%$ (range 10-66\%). For non-obese, non-overweight populations, the range was $0-1 \%$ [6]. Almost $90 \%$ of obese children and adolescents have at least one feature of metabolic syndrome [7]. On the basis of National Health and Nutrition Examination Survey (NHANES) 1999 to 2002 data, the prevalence of metabolic syndrome in adolescents 12 to 19 years old ranged from 0 to $9.4 \%$; variation in this estimate was the result of different criteria used to define metabolic syndrome [8]. In a report from (Biobank Standardisation and Harmonisation for Research Excellence in the European Union (BIOSHARE-EU), prevalence of metabolic syndrome in obese subjects ranged from 24 to $65 \%$ in females and from $\approx 43$ to $\approx 78 \%$ in males and substantially exceeded the prevalence in metabolically healthy obese subjects [9]. These divergences depended on the country.

In the light of children's dynamic growth and maturation, the population of children is unique. Obesity is diagnosed on the basis of centile charts, when BMI $\geq 95$ th centile. Moreover, according to The International Diabetes Federation (IDF) consensus-commonly used by most of the authors-metabolic syndrome may be recognized in children not younger than 10 years old [10]. It takes some time before metabolic syndrome complicates obesity. Nevertheless, the younger the child becomes obese, the earlier in life he or she might suffer from its complications [11]. However, one must remember that not all children suffering from obesity will develop MetS.

The aim of our study was to identify factors favoring the presence of one or all compounds of metabolic syndrome in obese children. Secondly, we analyzed the results in order to indicate which of them are modifiable.

\section{Materials and Methods}

This study was a part of the "6-10-14 for Health" integrated weight management program for children with overweight and obesity from Gdansk, Poland. The detailed design is available in previous publications and on request [12-14].

The analyzed data included children aged 10-12 years attending the intervention program in 2011-2015. Children were screened in primary schools and if overweight or obesity was diagnosed they were invited to the multidisciplinary, 12-month-long program. Patient flow is presented in Figure 1.

The demographic background of the participants was similar in the terms of ethnicity and socioeconomic status, however some minor discrepancies were present. The population of the City of Gdansk is over $99 \%$ Caucasian.

All the children were examined by pediatrician during the first intervention visit (including weight, height, and waist circumference measurement) and bioelectric impedance analysis (BIA) was performed. All the children were referred for blood tests within 4 weeks of the first visit.

Medical history was taken and collected data included body mass at birth (below $2.5 \mathrm{~kg}$ was assumed as hypotrophy, more than $4.0 \mathrm{~kg}$-macrosomy), parents' BMI, any metabolic disease in family members, sleeping disorders, and gastrointestinal complaints.

Body mass, BMI centile, waist circumference centiles, and blood pressure centiles were assessed using Polish centile charts, as recommended by the WHO [15-17]. Overweight was diagnosed if the BMI centile was $\geq 85$ th and obesity was diagnosed when BMI centile was $\geq 95$ th on the recommended centile charts [15].

Waist circumference (WC) over the 90th percentile and waist-hip ratio (WHR) $>0.8$ for girls and $>0.9$ for boys were interpreted as abnormal.

For children younger than 10 years old, waist-hip ratio (WhtR) seems to be more accurate than WC. Abnormal WhtR was defined when WhtR $\geq 0.5$. 


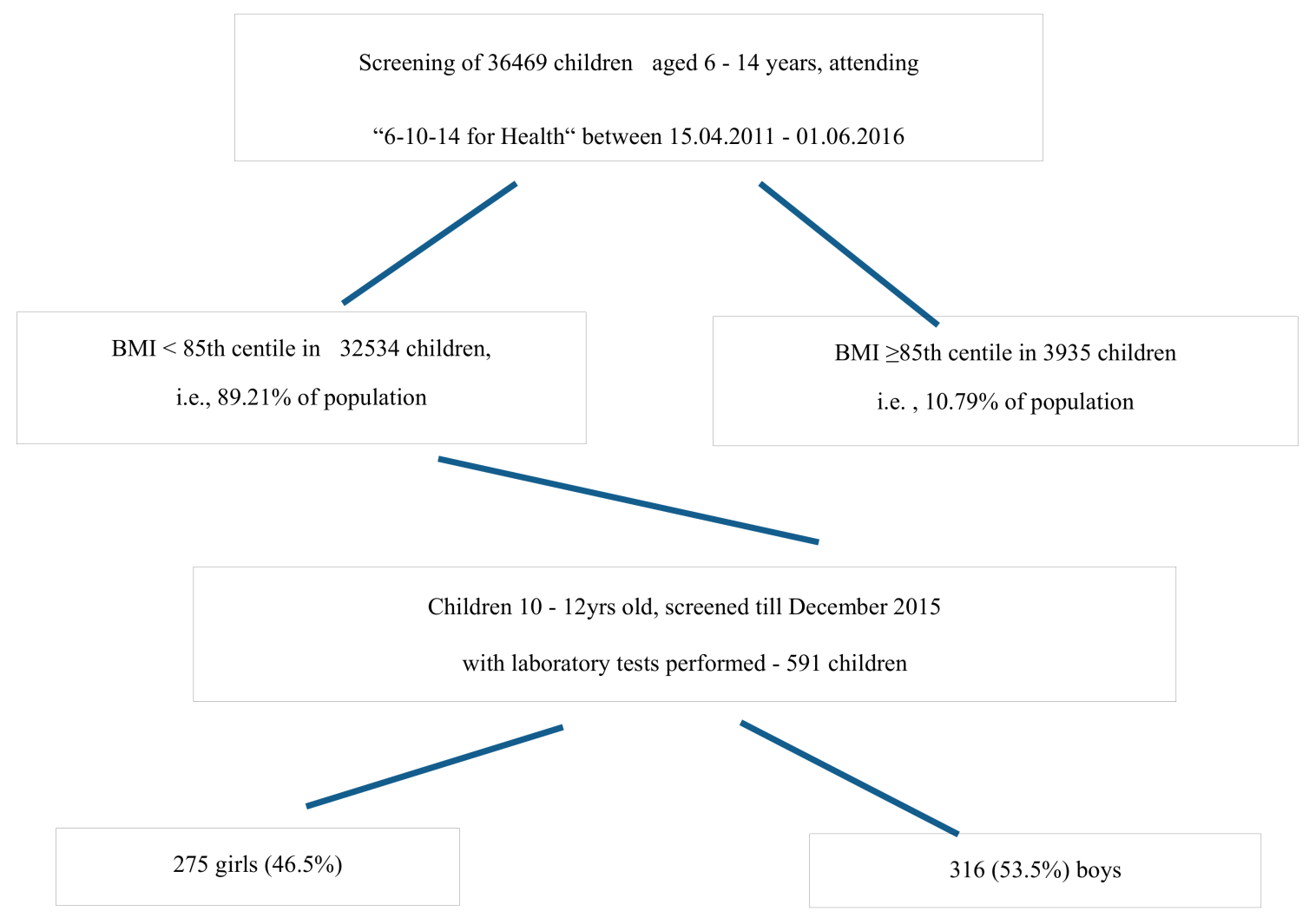

Figure 1. Patient screening and qualification for the study-study flow.

In our study, although all the participants were at least 10 years old, WhtR was also calculated.

The results of biometric impedance analysis were assessed according to standard values [18].

Lifestyle was evaluated on the basis of information obtained during the visit.

Physical activity was evaluated by means of a Kash Pulse Recovery Test [19-21] and classified as excellent, very good, good, moderate, poor, and very poor.

Nutritional habits were evaluated by a dietitian on the basis of recall data given by children and parents. Specific questions regarding quantity and quality of meals constituted the original questionnaire. Special attention was paid to breakfast (first course within $2 \mathrm{~h}$ after waking up) and dinner (last meal eaten $2 \mathrm{~h}$ before sleep), including the time of day.

Blood tests comprised aminotransferases, lipid fractions, thyroid stimulating hormone, tyrosine, $\mathrm{Hb} 1 \mathrm{c}$, and oral glucose tolerance test (OGTTs), along with insulin levels at the same time points, and the results were compared to standard values for appropriate age and sex.

Metabolic syndrome (MetS) was diagnosed according to IDF [22] in children with WC $>90$ th centile and at least two out of the following metabolic features: $\mathrm{HDL}<40 \mathrm{mg} / \mathrm{dL}$, TG $>150 \mathrm{mg} / \mathrm{dL}$, glycemia $>100 \mathrm{mg} / \mathrm{dL}$, and blood pressure $\geq 130 / 85 \mathrm{mmHg}$.

Statistical analyses included normal distribution of continuous variables, which was verified with the Shapiro-Wilk test [23]. Descriptive statistics are presented as the mean or median and standard deviation from the mean. Between-group comparisons were carried out using the Mann-Whitney U test and ANOVA Kruskal-Wallis test [23]. Nonparametric tests were chosen because of the large number of significant Shapiro tests, which were used for normality assumption assessment. All statistical tests were 2-tailed and performed at the 5\% level of significance. Statistical analysis was performed using Statistica 10 software (TIBCO Software Inc., Tulsa, OK, USA 2014). 
This study was accepted by the Independent Bioethics Committee for Scientific Research at the Medical University of Gdańsk (NKBBN/228/2012) on 25 June 2012. The study is registered in clinicaltrials.gov (NCT number: NCT04143074).

\section{Results}

591 children aged 10-12 years who entered the program, completed the questionnaire and had blood tests performed. None of the children had any chronic disease that could influence investigated parameters as well as no infection on the day of examination.

The girls were younger $(p=0.031)$, shorter $(p=0.028)$, and had lower WC $(p<0.0001)$, lower WHR $(p<0.0001)$, lower WhtR $(\mathrm{p}=0.002)$, and lower DBP $(p=0.044)$ compared to the boys. Moreover, higher BMI centile $(p<0.001)$ and higher fat tissue content were characteristic for girls. Elevated systolic blood pressure (SBP) was found in $10 \%$ of children, with no difference between girls and boys (Table 1).

Table 1. Results of anthropometry, blood pressure, and fat tissue content in the study population.

\begin{tabular}{|c|c|c|c|c|}
\hline \multicolumn{2}{|c|}{ Girls $(n=275)$} & \multicolumn{3}{|c|}{ Boys $(n=316)$} \\
\hline Mean & SD & mean & SD & $p$ \\
\hline 10.36 & 0.74 & 10.5 & 0.8 & 0.031 \\
\hline 148.3 & 7.89 & 149.7 & 7.7 & 0.028 \\
\hline 53.12 & 9.88 & 54 & 9.46 & 0.074 \\
\hline 24.01 & 2.88 & 24.1 & 2.73 & 0.541 \\
\hline 94.18 & 3.91 & 92.9 & 3.81 & 0.000 \\
\hline 76.46 & 7.34 & 78.85 & 7.58 & 0.000 \\
\hline 87.99 & 7.5 & 87.72 & 6.7 & 0.952 \\
\hline 0.87 & 0.07 & 0.9 & 0.09 & 0.000 \\
\hline 0.52 & 0.05 & 0.53 & 0.05 & 0.002 \\
\hline 112.61 & 11.77 & 112.87 & 11.4 & 0.820 \\
\hline 68.87 & 8.41 & 70.11 & 8.38 & 0.044 \\
\hline 33.08 & 4.56 & 27.61 & 5.42 & 0.000 \\
\hline
\end{tabular}

$p<0.05$ Mann-Whitney U test analysis.

Based on BMI percentile criterion there were 401 (67.9\%) overweight (BMI 85-95 centile) and 190 (32.1\%) obese children (BMI $\geq 95$ centile). Obesity was diagnosed in 85 (30.9\%) girls and in $105(33.2 \%)$ boys, whereas $190(69.1 \%)$ girls and $211(66.8 \%)$ boys were overweight. Girls had higher BMI centiles compared to boys $(p<0.0001)$.

Among $76(12.9 \%)$ children with metabolic syndrome there were 30 girls and 46 boys (Tables 2 and 3).

Table 2. Number of components of metabolic syndrome in girls and boys.

\begin{tabular}{llllllll}
\hline & Total & & Girls & \multicolumn{3}{c}{ Boys } & $p$ \\
\hline $\begin{array}{l}\text { Number of Components of } \\
\text { Metabolic Syndrome }(\boldsymbol{n})\end{array}$ & $\boldsymbol{n}$ & $\mathbf{\%}$ & $\boldsymbol{n}$ & $\mathbf{\%}$ & $\boldsymbol{n}$ & $\%$ & \\
0 & 243 & 41.1 & 119 & 43.3 & 124 & 39.2 & \\
1 & 272 & 46 & 126 & 45.8 & 146 & 46.2 & 0.239 \\
2 & 66 & 11.2 & 24 & 8.7 & 42 & 13.3 & \\
3 & 10 & 1.7 & 6 & 2.2 & 4 & 1.3 & \\
\hline$p<0.05$ Chi-square test analysis by sex. & & & & & &
\end{tabular}

Table 3. Number of girls and boys in Groups I, II and III.

\begin{tabular}{llllllll}
\hline Group & Total & \multicolumn{3}{c}{ Girls } & \multicolumn{3}{c}{ Boys } \\
\hline & $\boldsymbol{n}$ & $\%$ & $n$ & $\%$ & $n$ & $\%$ & \\
MetS+ & 76 & 12.9 & 30 & 10.9 & 46 & 14.6 & 0.349 \\
MetS- & 243 & 41.1 & 119 & 43.3 & 124 & 39.2 & \\
MetS+/- & 272 & 46 & 126 & 45.8 & 146 & 46.2 & \\
\hline
\end{tabular}

$p<0.05$ Chi-square test analysis. 
$73 \%$ of children with MetS had elevated blood pressure in comparison with $1.1 \%$ of children from groups II and III ( $p=0.005)$.

Reduced levels of HDL $(<40 \mathrm{mg} / \mathrm{dL})$ were found in all the children with MetS and in $27.6 \%$ of the remaining children (i.e., groups II and III), which was significantly different $(p=0.029)$. More than half of participants with MetS $(55.3 \%)$ had increased TG concentration compared to $4 \%$ of the remaining children $(p=0.001)$.

\subsection{Analysis of Prevalence of Proposed Risk Factors of MetS}

To achieve this aim we compared children constituting group I (MetS+) to the rest of the children i.e., groups II and III (Met- and MetS+/-).

According to medical history, hypotrophy at birth was three times more prevalent in boys with MetS than in boys without MetS. Discerning gender showed that low birth weight was more prevalent in boys with MetS $(p=0.034)$. All the girls with MetS were eutrophic at birth.

Further analyses revealed that $47.3 \%$ of fathers of children with MetS were obese and $14.5 \%$ fathers had normal body mass. Maternal BMI did not differ between the groups.

There was no difference between the subgroups in terms of analyzed metabolic diseases (DM2, hypothyroidism, MetS, or dyslipidemia) in children's parents. Similarly, prevalence of cardiovascular diseases in parents was not significant.

The correlation between metabolic syndrome and its components was significant for

- Paternal obesity $(p=0.023)$;

- Obesity in at least one parent $(p=0.046)$;

- Low body mass at birth in boys $(p=0.046)$.

\subsection{Nutrition Analysis Based on Medical History and Recall Questionnaire}

The results provided that children with MetS (44.7\%) omitted breakfast more often than children from group II (35\%) and group III $(28.7 \%)(p=0.03)$. This phenomenon was especially distinctive in boys.

Therefore, not eating breakfast was a risk factor not only for MetS $(p=0.027, \mathrm{OR}=1.74$; 95\%CI: 1.06-2.87) but also for at least one of its components $(p=0.036)(\mathrm{OR}=1.46$; 95\% CI: 1.02-2.09).

Omitting dinner was more prevalent in children from groups I and III $(\mathrm{OR}=1.63$; $95 \%$ CI: $1.13-2.35)$ as well as in boys (OR $=2.66 ; 95 \%$ CI: $1.56-4.55)$ (see Supplementary Table S3, Additional File S1). Not eating dinner seems to be another risk factor for MetS.

On the other hand, there were no differences in eating fruit or vegetables (in terms of quantity and frequency) between children with MetS and the rest of the study population.

\subsection{Physical Activity}

The physical performance results (evaluated by the Kash Pulse Recovery Test) are presented in Supplementary Table S4, Additional File S1. This shows that children with MetS had very poor physical performance, three times more often than the rest of the children. However, boys with MetS had significantly worse physical performance than the rest of the males $(p=0.15)$.

The correlation between metabolic syndrome and its components was significant for

- Omitting dinner: in the whole population (OR $=1.63$; 95\% CI: $1.13-2.35)$, especially in boys $(\mathrm{OR}=2.66$; $95 \% \mathrm{CI}$ : $1.56-4.55)$;

- $\quad$ Not eating breakfast $(p=0.036)(\mathrm{OR}=1.46 ; 95 \%$ CI: $1.02-2.09)$.

Biochemical assessment

Elevated levels of insulin were most common in children with MetS; twice as much as in children from group II and fourfold than in group III. Significantly, more obese children without MetS had normal insulin levels $(p=0.001)$ (Table 4$)$. 
Table 4. Fasting insulin level (Ins), one and two hours after glucose intake (oral glucose tolerance test (OGTT)) in study population.

\begin{tabular}{|c|c|c|c|c|c|c|c|c|c|}
\hline \multirow[b]{2}{*}{ Fasting insulin level } & \multicolumn{2}{|c|}{ MetS+ } & \multicolumn{2}{|c|}{ MetS- } & \multicolumn{2}{|c|}{ MetS+l- } & \multirow{4}{*}{$\begin{array}{l}\text { MetS+ vs. } \\
\text { MetS- vs. } \\
\text { MetS+l- } \\
p \text {-Value } \\
0.001\end{array}$} & \multirow{4}{*}{$\begin{array}{l}\text { MetS+ and } \\
\text { MetS+l- vs. } \\
\text { MetS- } \\
0.001\end{array}$} & \multirow{4}{*}{$\begin{array}{l}\text { MetS+ vs. } \\
\text { MetS- and } \\
\text { MetS+l- } \\
0.001\end{array}$} \\
\hline & $n$ & $\%$ & $n$ & $\%$ & $n$ & $\%$ & & & \\
\hline Elevated $(\geq 15 \mathrm{ng} / \mathrm{mL})$ & 37 & 48.6 & 32 & 13.2 & 59 & 21.7 & & & \\
\hline Normal (<15 ng/mL) & 39 & 51.4 & 211 & 86.8 & 213 & 78.3 & & & \\
\hline (Ins) after $1 \mathrm{~h}$ OGTT & $n$ & $\%$ & $n$ & $\%$ & $n$ & $\%$ & \multirow{6}{*}{0.015} & \multirow{6}{*}{0.076} & \multirow{6}{*}{0.831} \\
\hline Elevated & 6 & 7.9 & 3 & 1.2 & 14 & 5.1 & & & \\
\hline Normal & 70 & 92.1 & 240 & 98.8 & 258 & 94.9 & & & \\
\hline (Ins) after 2 h OGTT & $n$ & $\%$ & $n$ & $\%$ & $n$ & $\%$ & & & \\
\hline Elevated & 23 & 30.3 & 19 & 7.9 & 39 & 14.3 & & & \\
\hline Normal & 53 & 69.7 & 224 & 92.1 & 233 & 85.7 & & & \\
\hline
\end{tabular}

$p<0.05$ Kruskal-Wallis test analysis.

Insulin resistance was also more common in children with MetS compared to the remaining children (Table 5).

Table 5. Glucose concentration in study population during oral glucose test.

\begin{tabular}{|c|c|c|c|c|c|c|c|c|c|}
\hline \multirow{2}{*}{$\begin{array}{l}\text { Glucose concentration } \\
\text { Fasting } \\
\end{array}$} & \multicolumn{2}{|c|}{ MetS+ } & \multicolumn{2}{|c|}{ MetS- } & \multicolumn{2}{|c|}{ MetS+l- } & \multirow{2}{*}{$\begin{array}{l}\text { MetS+ vs. } \\
\text { MetS- vs. } \\
\text { MetS+/- } \\
p \text {-Value }\end{array}$} & \multirow[t]{2}{*}{$\begin{array}{l}\text { MetS+ and } \\
\text { MetS+I- vs. } \\
\text { MetS- }\end{array}$} & \multirow[t]{2}{*}{$\begin{array}{l}\text { MetS+ vs. } \\
\text { MetS - and } \\
\text { MetS+l- }\end{array}$} \\
\hline & $n$ & $\%$ & $n$ & $\%$ & $n$ & $\%$ & & & \\
\hline$<100 \mathrm{mg} / \mathrm{dL}$ & 50 & 65.8 & 243 & 100 & 244 & 89.7 & 0.001 & 0.001 & 0.001 \\
\hline $100-125 \mathrm{mg} / \mathrm{dL}$ & 21 & 27.6 & 0 & 0 & 27 & 9.9 & 0.015 & 0.001 & 0.015 \\
\hline$\geq 126 \mathrm{mg} / \mathrm{dL}$ & 5 & 6.6 & 0 & 0 & 1 & 0.4 & 0.015 & 0.015 & 0.010 \\
\hline$>200 \mathrm{mgL}$ & 0 & 0 & 0 & 0 & 0 & 0 & & & \\
\hline \multicolumn{10}{|c|}{ One hour after glucose intake } \\
\hline Norm & 75 & 98.7 & 243 & 100 & 272 & 100 & & & \\
\hline$>200 \mathrm{mg} / \mathrm{dL}$ & 1 & 1.3 & 0 & 0 & 0 & 0 & 0.985 & 0.985 & 0.961 \\
\hline \multicolumn{10}{|c|}{ Two hours after glucose intake } \\
\hline Normal $<140 \mathrm{mg} / \mathrm{dL}$ & 5 & 6.7 & 5 & 2.1 & 13 & 4.7 & & & \\
\hline Elevated $140-199 \mathrm{mg} / \mathrm{dL}$ & 71 & 93.3 & 238 & 97.9 & 259 & 95.3 & 0.201 & 0.350 & 0.148 \\
\hline$>200 \mathrm{mg} / \mathrm{dL}$ & 0 & 0 & 0 & 0 & 0 & 0 & & & \\
\hline
\end{tabular}

Five children with MetS had fasting glucose $>126 \mathrm{mg} / \mathrm{dl}$ and were consulted by a diabetologist.

Children without MetS had normal fasting glucose concentration, whereas children from groups I and III were pathological in $27.6 \%$ cases and $9.9 \%$ cases, respectively.

Abnormal Homeostatic Model Assessment for Insulin Resistance (HOMA-IR) values were significantly more common in children with metabolic syndrome $(p=0.005)$ (Table 6).

Although children with MetS had elevated aminotransferase activity more often, the difference was significant for Alanine transaminase (ALT) only $(p=0.011)$. Hypertriglyceridemia, Hyperglycemia and lower HDL concentration were similar in boys and girls. (Table S1). Nevertheless, the mean values of these parameters differed: boys had higher concentration of glucose and HDL and lower TG concentration (Table S2). 
Table 6. HOMA-IR values (normal and elevated) in study subgroups.

\begin{tabular}{|c|c|c|c|c|c|c|c|c|c|}
\hline \multirow[t]{2}{*}{ HOMA-IR } & \multicolumn{2}{|c|}{ MetS+ } & \multicolumn{2}{|c|}{ MetS- } & \multicolumn{2}{|c|}{ MetS+I- } & \multirow{2}{*}{$\begin{array}{l}\text { MetS+ vs. } \\
\text { MetS- vs. } \\
\text { MetS+l- } \\
p \text {-Value }\end{array}$} & \multirow{2}{*}{$\begin{array}{l}\text { MetS+ and } \\
\text { MetS+/- Vs. } \\
\text { +MetS- }\end{array}$} & \multirow{2}{*}{$\begin{array}{l}\text { MetS+ Vs. } \\
\text { MetS- and } \\
\text { MetS+/- }\end{array}$} \\
\hline & $n$ & $\%$ & $n$ & $\%$ & $n$ & $\%$ & & & \\
\hline Over $\geq 2.5$ & 58 & 76.3 & 32 & 13.2 & 86 & 31.7 & \multirow{2}{*}{0.005} & \multirow{2}{*}{0.009} & \multirow{2}{*}{0.001} \\
\hline Normal i.e., $<2.5$ & 18 & 23.7 & 211 & 86.8 & 186 & 68.3 & & & \\
\hline
\end{tabular}

$p<0.05$ Kruskal-Wallis test analysis.

\section{Discussion}

The prevalence of obesity is high worldwide and some describe it as pandemic. This disease is known to be one of the so-called "lifestyle diseases" and it develops mostly in adolescence and adulthood. However, the incidence of obesity in children is growing fast and the burdens of its complications must be considered not only from a medical but also a socioeconomic point of view.

Obesity increases the risk of other diseases of affluence such as hypertension, dyslipidemia, and glucose intolerance, and at the same time it is a well-known risk factor for CVD and MetS [24-27].

Many authors have reported that children with a BMI over the 75th centile have higher morbidity and mortality due to DM2 and CVD in adulthood [28-31]. Thus, quality and expectancy of life certainly is and will be affected by obesity.

Metabolic syndrome has become the epitome of obesity's complications with a high impact on human wellbeing.

Despite various definitions of MetS in children, apparently not all teenagers with obesity will develop metabolic syndrome or even one of its components. Which obese children (and in fact which of the whole obese population) are especially predisposed to MetS is still not fully understood. However, being aware of the risk factors for metabolic syndrome might allow prevention of MetS or at least minimize its prevalence and consequences.

In our study, $12.9 \%$ of obese children 9-12 years old, participating in "6-10-14 for Health" had metabolic syndrome diagnosed-10.9\% of girls and $14.6 \%$ of boys. These results are similar to those in other publications [32]. It seems that prevalence of obesity and metabolic syndrome in children is more or less the same all over the world. Taking into consideration sociodemographic variables, differences in religion, economic status, etc., there must be some stand-alone background.

According to Abdullah et al., young age at the onset of obesity, as well as the time period for which obesity lasts, are essential factors for MetS in adolescence [33]. Clearly, appropriate prophylaxis should be undertaken as soon as possible to stop this process.

Our main aim was to identify children who were at the highest risk of developing MetS. Recognition of predisposing agents which can be modified may be crucial, since it is our deep belief that not undertaking any prevention will eventually lead to MetS.

The results show that obese children with metabolic syndrome are characterized by poor physical performance, bad nutrition habits, and glucose intolerance with insulin resistance.

It is hard to say whether poor physical performance is secondary to obesity and MetS, or rather the reason for these. Contemporary lifestyle with ubiquitous hi-technology, and fast, mechanized transportation, do not mobilize children to undertake physical activity. A sedentary lifestyle also favors certain nutritional choices, including fast-foods, snacks, and sweet beverages-all high-sugar, high-fat products.

Similarly to Mazur et.al., we also found that pathological WhtR predisposes children to both MetS and certain components of the syndrome [34].

In our study, we found that boys with low body mass at birth more often had MetS. Obviously this fact is irreversible, but nevertheless it is known that metabolic programming, which begins in fetal life, carries on after birth. There is a slight opportunity to influence this process by means of a healthy lifestyle for pregnant woman and this can be 
achieved by educating not only doctors and health providers but also mothers. Promoting breastfeeding exclusively with recommended weaning time is an easy way to influence metabolic programming and weight gain in the first 2-3 years of life.

Both or either parent's obesity - especially the father's-might suggest genetic predisposition to excess body mass in a child, but, on the other hand, it could illustrate the family's lifestyle. It is already known that obese children skip breakfast more often than healthy children [35]. Contrary to some authors, we also found that omitting dinner is related to metabolic syndrome or to components of it.

This feeding pattern fits into the modern model of life, characterized additionally by little physical activity and much sedentary time (at school, work, and home). Similar observations have already been published [36].

The recall data collection is undoubtedly the limitation of this study. Both interviews and questionnaires have flaws. Respondents may have not given accurate answers. Moreover, the recall data most probably are not precise and are rather "approximate"; some information may also have been omitted.

In some cases the prospective dietary records were ordered, but could be verified only after the first interventional visit (i.e., during the 2nd or even 3rd visits, when the recommended actions should have been implemented). The strengths of this study, however, were the number of subjects and detailed lifestyle and laboratory evaluation, as well the performance of a test to assess physical fitness - these are rarely performed in population studies in children.

One cannot precisely assess what is a result of genetic involvement and what is a result of a family's habits in the development of obesity. Nevertheless, the latter can be modified. However, if genetic predisposition runs in the family, this is a red flag and preventive measurements should be undertaken in order to minimize the unavoidable consequences of obesity and MetS.

Sound knowledge and education on energy balance (via proper diet and physical activity) should be promoted as a driving force against obesity. Changes implemented for a child's benefit will benefit the whole family.

To our knowledge this is the first study on the factors predisposing obese children and teenagers to metabolic syndrome that has been carried out in such a large, homogenous population (age, residency).

Taking into account genetic predisposition and environmental influences, we tried to indicate modifiable risk factors.

The results of our study could be used as warning signals for subjects who are genetically predisposed to obesity. In these children certain preventive measures should be taken. Although, unfortunately, it has become a catchphrase, physical activity and a healthy diet are the best way to lessen the risk of severe complications from obesity and metabolic syndrome itself.

\section{Conclusions}

Among the many risk factors of metabolic syndrome, besides those that are irreversible (such as body mass at birth, gender, genetic predisposition, etc.) there are many factors that are dependent on lifestyle. Proper, increased physical activity and rational nutrition (regular healthy meals) can be modified and, by this, the risk of metabolic syndrome in obese children can be diminished in an inexpensive way.

Education and preventive companies addressing health providers and parents are required in order to lessen morbidity in relation to obesity and metabolic syndrome or at least minimize their prevalence and consequences.

Intervention programs addressed to all overweight and obese children, especially those who are at risk of metabolic syndrome, should be designed (preferably on an international level). 
Supplementary Materials: The following are available online at https: / www.mdpi.com/1660-4 601/18/3/1060/s1, Additional file S1. Table S1: Mean glucose, triglycerides (TG) and high density lipids (HDL) concentration in study population. Table S2: Comparison of glycemia, TG and HDL abnormalities between boys and girls. Table S3. Dinner consumption in the study population; Table S4 Physical performance analysis.

Author Contributions: A.J.: design of the work, patient recruitment, data collection and analysis, paper drafting, revision and approval of the manuscript, M.B.: design of the work, substantive revision, approval of the manuscript, A.R.-S.: design of the work; analysis and interpretation of data, patient recruitment, data collection and analysis, approval of the manuscript, A.S.-S.: design work, revision and approval of the manuscript. All authors have read and agreed to the published version of the manuscript.

Funding: The City of Gdansk authorities. The City of Gdansk had no financial input into the presented manuscript, nor did they have any impact on the design of the study or collection, analysis, and interpretation of data, or in the writing of the manuscript.

Institutional Review Board Statement: The study was conducted with the approval of an independent bioethics committee at the Medical University of Gdańsk (NKBBN/228/2012.), 25th June 2012 in accordance with the requirements of the Helsinki Declaration. Each parent/legal guardian had to express written consent to the child's participation in the programme.

Informed Consent Statement: Informed consent was obtained from all subjects involved in the study.

Data Availability Statement: Availability of data and materials: the data that support the findings of this study are available] but restrictions apply to the availability of these data, which were used under license for the current study, and so are not publicly available. Data are, however, available from the authors upon reasonable request and with permission of "6-10-14 for Health" integrated weight management program for children with overweight and obesity from Gdansk, Poland.

Acknowledgments: We thank our colleagues from "6-10-14 for Health" for their hard work and engagement. Most of all we would like to thank our patients and their parents for their trust in our work.

Conflicts of Interest: The authors declare no conflicts of interest.

\section{References}

1. Obesity and Overweight. Available online: https://www.who.int/news-room/fact-sheets/detail/obesity-and-overweight (accessed on 30 March 2020).

2. Bentham, J.; Di Cesare, M.; Bilano, V.; Bixby, H.; Zhou, B.; Stevens, G.A.; Riley, L.M.; Taddei, C.; Hajifathalian, K.; Lu, Y.; et al. Worldwide trends in body-mass index, underweight, overweight, and obesity from 1975 to 2016: A pooled analysis of 2416 population-based measurement studies in 128.9 million children, adolescents, and adults. Lancet 2017, 390, $2627-2642$.

3. Dixon, J.B.; Zimmet, P.; Alberti, K.G.; Rubino, F. International Diabetes Federation Position Statement on Bariatric Surgery. Diabet. Med. 2011, 28, 628-642. [CrossRef] [PubMed]

4. Silventoinen, K.; Jelenkovic, A.; Sund, R.; Hur, Y.M.; Yokoyama, Y.; Honda, C.; Hjelmborg, J.B.; Moller, S.; Ooki, S.; Aaltonen, S.; et al. Genetic and environmental effects on body mass index from infancy to the onset of adulthood: An individual-based pooled analysis of 45 twin cohorts participating in the COllaborative project of Development of Anthropometrical measures in Twins (CODATwins) study. Am. J. Clin. Nutr. 2016, 104, 371-379. [PubMed]

5. Gortmaker, S.L.; Swinburn, B.A.; Levy, D.; Carter, R.; Mabry, P.L.; Finegood, D.T.; Huang, T.; Marsh, T.; Moodie, M.L. Changing the future of obesity: Science, policy, and action. Lancet 2011, 378, 838-847. [CrossRef]

6. Friend, A.; Craig, L.; Turner, S. The prevalence of metabolic syndrome in children: A systematic review of the literature. Metab. Syndr. Relat. Disord. 2013, 11, 71-80. [CrossRef]

7. Cook, S.; Weitzman, M.; Auinger, P.; Nguyen, M.; Dietz, W.H. Prevalence of a metabolic syndrome phenotype in adolescents: Findings from the Third National Health and Nutrition Examination Survey, 1988-1994. Arch. Pediatr. Adolesc. Med. 2003, 157, 821-827. [CrossRef]

8. Laurson, K.R.; Welk, G.J.; Eisenmann, J.C. Diagnostic performance of BMI percentiles to identify adolescents with metabolic syndrome. Pediatrics 2014, 133, e330-e338. [CrossRef]

9. Van Vliet-Ostaptchouk, J.V.; Nuotio, M.L.; Slagter, S.N.; Doiron, D.; Fischer, K.; Foco, L.; Gaye, A.; Gögele, M.; Heier, M.; Hiekkalinna, T.; et al. The prevalence of metabolic syndrome and metabolically healthy obesity in Europe: A collaborative analysis of ten large cohort studies. BMC Endocr. Disord. 2014, 14, 9. [CrossRef]

10. Zimmet, P.; Alberti, G.K.M.M.; Kaufman, F.; Tajima, N.; Silink, M.; Arslanian, S.; Wong, G.; Bennett, P.; Shaw, J.; Caprio, S. The metabolic syndrome in children and adolescents-An IDF consensus report. Pediatr. Diabetes 2007, 8, 299-306. [CrossRef] 
11. Tanamas, S.K.; Wong, E.; Backholer, K.; Abdullah, A.; Wolfe, R.; Barendregt, J.; Peeters, A. Duration of obesity and incident hypertension in adults from the Framingham Heart Study. J. Hypertens. 2015, 33, 542-545. [CrossRef]

12. Brzezinski, M.; Jankowski, M.; Niedzielska, A.; Danielewicz, A.; Czarnecka, P. Health program "6-10-14 for Health" as an example of comprehensive environmental activities in the field of children obesity. Study protocol and primary results. Appetite 2014, 76, 202.

13. Szlagatys-Sidorkiewicz, A.; Brzeziński, M.; Jankowska, A.; Metelska, P.; Słomińska-Fraczek, M.; Socha, P. Long-term effects of vitamin D supplementation in vitamin D deficient obese children participating in an integrated weight-loss programme (a double-blind placebo-controlled study)—Rationale for the study design. BMC Pediatr. 2017, 17, 97. [CrossRef] [PubMed]

14. Brzeziński, M.; Metelska, P.; Myśliwiec, M.; Szlagatys-Sidorkiewicz, A. Lipid disorders in children living with overweight and obesity-Large cohort study from Poland. Lipids Health Dis. 2020, 19, 47. [CrossRef] [PubMed]

15. Kułaga, Z.; Litwin, M.; Tkaczyk, M.; Palczewska, I.; Zajączkowska, M.; Zwolińska, D.; Krynicki, T.; Wasilewska, A.; Moczulska, A.; Morawiec-Knysak, A.; et al. Polish 2010 growth references for school-aged children and adolescents. Eur. J. Pediatr. 2011, 170, 599-609. [CrossRef]

16. Świąder-Leśniak, A.; Kułaga, Z.; Grajda, A.; Gurzkowska, B.; Góźdź, M.; Wojtyło, M.; Różdżyńska-Świątkowska, A.; Litwin, M. Wartości referencyjne obwodu talii i bioder polskich dzieci i młodzieży w wieku 3-18 lat References for waist and hip circumferences in Polish children and adoles-cents 3-18 year of age. Stand. Med. 2015, 12, 137-150.

17. Kułaga, Z.; Litwin, M.; Grajda, A.; Kułaga, K.; Gurzkowska, B.; Góźdź, M.; Pan, H. Oscillometric blood pressure percentiles for Polish normal-weight school-aged children and adolescents. J. Hypertens. 2012, 30, 1942-1954. [CrossRef]

18. Leppik, A.; Jürimäe, T.; Jürimäe, J. Influence of anthropometric parameters on the body composition measured by bioelectrical impedance analysis or DXA in children. Acta Paediatr. 2004, 93, 1036-1041. [CrossRef]

19. Jankowski, M.; Niedzielska, A.; Brzezinski, M.; Drabik, J. Cardiorespiratory fitness in children: A simple screening test for population studies. Pediatr. Cardiol. 2015, 36, 27-32. [CrossRef]

20. Beutner, F.; Ubrich, R.; Zachariae, S.; Engel, C.; Sandri, M.; Teren, A.; Gielen, S. Validation of a brief step-test protocol for estimation of peak oxygen uptake. Eur. J. Prev. Cardiol. 2015, 22, 503-512. [CrossRef]

21. Cole, C.R.; Blackstone, E.H.; Pashkow, F.J.; Snader, C.E.; Lauer, M.S. Heart-rate recovery immediately after exercise as a predictor of mortality. N. Engl. J. Med. 1999, 341, 1351-1357. [CrossRef]

22. Alberti, S.G.; Zimmet, P. The IDF Consensus definition of the Metablic Syndrome in Children and Adolescents. Int. Diabetes Fed. 2007, 24, 2-930229.

23. Upton, G.; Cook, I. A Dictionary of Statistics; Oxford University Press: Oxford, UK, 2008.

24. Turer, C.B.; Brady, T.M.; de Ferranti, S.D. Obesity, Hypertension, and Dyslipidemia in Childhood Are Key Modifiable Antecedents of Adult Cardiovascular Disease: A Call to Action. Circulation 2018, 137, 1256-1259. [CrossRef]

25. Magge, S.N.; Goodman, E.; Armstrong, S.C.; Daniels, S.; Corkins, M.; De Ferranti, S.; Golden, N.H.; Kim, J.H.; Schwarzenberg, S.J.; Assar, C.L.; et al. The metabolic syndrome in children and adolescents: Shifting the focus to cardiometabolic risk factor clustering Pediatrics 2017, 140, e20171603. [CrossRef]

26. Adamo, E.D.; Guardamagna, O.; Chiarelli, F.; Bartuli, A.; Liccardo, D.; Ferrari, F.; Nobili, V. Atherogenic Dyslipidemia and Cardiovascular Risk Factors in Obese Children. Int. J. Endocrinol. 2015. [CrossRef]

27. Jimenez-Rivera, C.; Hadjiyannakis, S.; Davila, J.; Hurteau, J.; Aglipay, M.; Barrowman, N.; Adamo, K.B. Prevalence and risk factors for non-alcoholic fatty liver in children and youth with obesity. BMC Pediatr. 2017, 17, 113. [CrossRef] [PubMed]

28. Spiotta, R.T.; Luma, G.B. Evaluating Obesity and Cardiovascular Risk Factors in Children and Adolescents. Am. Fam. Physician 2008, 78, 1052-1058.

29. Freedman, D.S.; Mei, Z.; Srinivasan, S.R.; Berenson, G.S.; Dietz, W.H. Cardiovascular Risk Factors and Excess Adiposity among Overweight Children and Adolescents: The Bogalusa Heart Study. J. Pediatr. 2007, 150, 12-17.e2. [CrossRef] [PubMed]

30. Eriksson, J.; Forsén, T.; Osmond, C.; Barker, D. Obesity from cradle to grave. Int. J. Obes. 2003, 27, 722-727. [CrossRef]

31. Gaston, S.A.; Tulve, N.S.; Ferguson, T.F. Abdominal obesity, metabolic dysfunction, and metabolic syndrome in U.S. adolescents: National Health and Nutrition Examination Survey 2011-2016. Ann. Epidemiol. 2019, 30, 30-36. [CrossRef]

32. Szabelska-Zakrzewska, K.; Durko, A.; Socha-Banasiak, A.; Majewska, M.; Kolejwa, M.; Kazanek-Zasada, J.; Czkwianianc, E. Metabolic syndrome in overweight or obese children and adolescents based on own material Abstract Key words. Dev. Period Med. 2018, 22, 351-357.

33. Abdullah, A.; Stoelwinder, J.; Shortreed, S.; Wolfe, R.; Stevenson, C.; Walls, H.; De Courten, M.; Peeters, A. The duration of obesity and the risk of type 2 diabetes. Public Health Nutr. 2011, 14, 119-126. [CrossRef] [PubMed]

34. Mazur, A.; Klimek, K.; Małecka-Tendera, E. Postprandial metabolic and hormonal response to meals with varying carbohydrate content (preliminary examination). Endocrinol. Obes. Metab. Disord. 2012, 8, 44-52.

35. Szajewska, H.; Ruszczyński, M. Systematic review demonstrating that breakfast consumption influences body weight outcomes in children and adolescents in Europe. Crit. Rev. Food Sci. Nutr. 2010, 50, 113-119. [CrossRef] [PubMed]

36. Hong, I.; Coker-Bolt, P.; Anderson, K.R.; Lee, D.; Velozo, C.A. Relationship between physical activity and overweight and obesity in children: Findings from the 2012 National Health and Nutrition Examination Survey National Youth Fitness Survey. Am. J. Occup. Ther. 2016, 70, 7005180060p1-7005180060p8. [CrossRef] [PubMed] 